\section{sciendo}

DOI: 10.2478/ncr-2018-0002

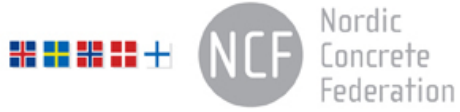

ISSN online 2545-2819

ISSN print $\quad 0800-6377$

Received: Feb. 6, 2018

Revision received: April 18, 2018

Accepted: April 18, 2018
(C) Article authors. This is an open access article distributed under the Creative Commons Attribution-NonCommercial-NoDerivs licens. (http://creaticecommons.org/licenses/by.nc-nd/3.0/).

\title{
Reduction of Radon Gas in Concrete Using Admixtures and Additives
}

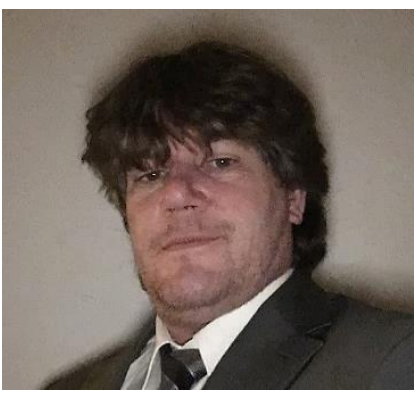

Magnus Döse

Doctoral candidate, The Royal Institute of Technology (KTH)

Department of Civil and Architectural Engineering, Concrete Structures

The Swedish Cement and Concrete Research Institute (CBI)

Brinellgatan 4, SE-501 15 Borås

e-mail:magnus.dose@cbi.se

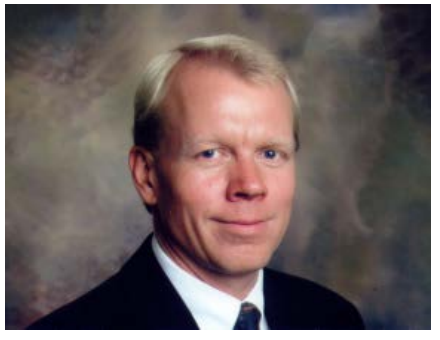

Johan Silfwerbrand

Professor, The Royal Institute of Technology (KTH)

Department of Civil and Architectural Engineering, Concrete

Structures

Brinellvägen 23, SE-100 44 Stockholm

e-mail: jsilfwer@kth.se

\begin{abstract}
The second largest cause of lung cancer is related to radon $\left({ }^{222} \mathrm{Rn}\right)$ and its progenies in our environment. Building materials, such as concrete, contribute to the production of radon gas through the natural decay of ${ }^{238} \mathrm{U}$ from its constituents. The Swedish Cement and Concrete Research Institute (CBI) has examined three concrete recipes where only an additive as well as fly ash were added as single constituents to a reference recipe and compared to a reference concrete. The inputs of an additive as well as a supplementary cementitious material (fly ash) were made as a mean to investigate their potential influence on the radon exhalation rates of the concrete. Measurements were performed with an ATMOS 33 ionizing pulsation chamber for at least five different occasions for each recipe during a 22 month period. The results indicate a reduction of the exhalation rate by approximately 30-35 \% for each altered recipe. This means roughly 1.5-2 mSv per year decrease in effective dose to a human using an additive or a supplementary cementitious material such as fly ash in relation to the investigated standard concrete.
\end{abstract}


Key words: radon, effective dose, concrete, building materials, admixtures, additives, fly ash, health.

\section{INTRODUCTION AND BACKGROUND}

\subsection{Ionizing radiation and health}

The second largest cause of lung cancer is ionizing radiation generated by radon and its progenies [1]. The EU legislation, its Construction Products Regulations [2] and the EU's Basic Safety Standards (BSS) directive [3] currently put a strong focus on ionizing radiation of building materials and safety for the public. In 2018 the implementation of the current BSS should be fulfilled in the European countries' national legislation. From a national standpoint the increase in environmental awareness is noticed by adequate procurements involving legal certification documents in the building process relating to environmental issues for public health. The world health organization (WHO) also recommends a maximum radon level of $100 \mathrm{~Bq} / \mathrm{m}^{3}$ due to large inter-pooling studies by Darby et al. [4] showing a clear link with increased mortality due to increase of radon in households.

Radon being a noble gas in the transformation chain of ${ }^{238} \mathrm{U}$ was thoroughly monitored as an environmental risk to habitants in Swedish households in the 1980's [5]. A large part of the Swedish building stock is composed by concrete. However, in response to environmental goals by the national authorities the increased use of crushed bedrock instead of glaciofluvial sediments may in part increase the risks. The ${ }^{238} \mathrm{U}$ and ${ }^{232} \mathrm{Th}$ content in the crushed bedrock is higher than in natural glacofluvial material. According to Jelinek and Eliasson [6] glaciofluvial materials, especially sands, have lower thorium and uranium levels compared to equivalent bedrock that has not been physically or chemically broken down. This is due to leaching through percolation of water and natural sorting processes that "flushes" the radioactive isotopes out from the coarser fractions, whilst they are enriched in the finer particle size fractions (clay and silt) [6].

Stranden [7] presented in experiments that the important parameters of radon exhalation of building materials primarily are; permeability, porosity, moisture, pressure gradient and temperature of the material. Since the temperature and pressure gradient are factors that have been set equal in this study, permeability of the material and its porosity and moisture content are the remaining key parameters.

The permeability is in part related to the porosity of the material [7, 8, 9, and 10]. Using Fick's first law of mass transfer, a diffuse flow through a material under a steady state condition of a radon source concentration, can be determined. The porosity could be related to diffusion through a material [9] according to

$$
p=D / D_{e}
$$

where, $D$ is the diffusion coefficient $\left(\mathrm{m}^{2} / \mathrm{s}\right)$ and $D_{e}$, the effective diffusion coefficient $\left(\mathrm{m}^{2} / \mathrm{s}\right)$. The effective diffusion coefficient relates to the air voids in the system, while the diffusion coefficient relates to the areal cross section of the (bulk) material investigated. 
The radon diffusion coefficients can be expressed as the diffusion length $L(\mathrm{~m})$ as to give a measure of how much radon that are exhaled before $50 \%$ of the radon is decayed. Using the radon decay constant $\lambda\left(\mathrm{s}^{-1}\right)$, the diffusion relates to the radon diffusion length according to

$$
L=\sqrt{D / \lambda}
$$

The relative humidity $(\mathrm{RH})$ or moisture content within the concrete is also a key ingredient in the transport mechanism of radon [7, 11]. Particularly, it is interesting how this impact reflects upon the exhalation rate of radon during hydration. The influence of relative humidity and moisture content of concrete on the radon exhalation rate was examined and modelled by Cozmuta et al. [11] for a concrete receipt with a w/c-ratio of 0.38 . Figure 1 presents the modelled curve of exhalation of radon as a function of relative humidity within the concrete.

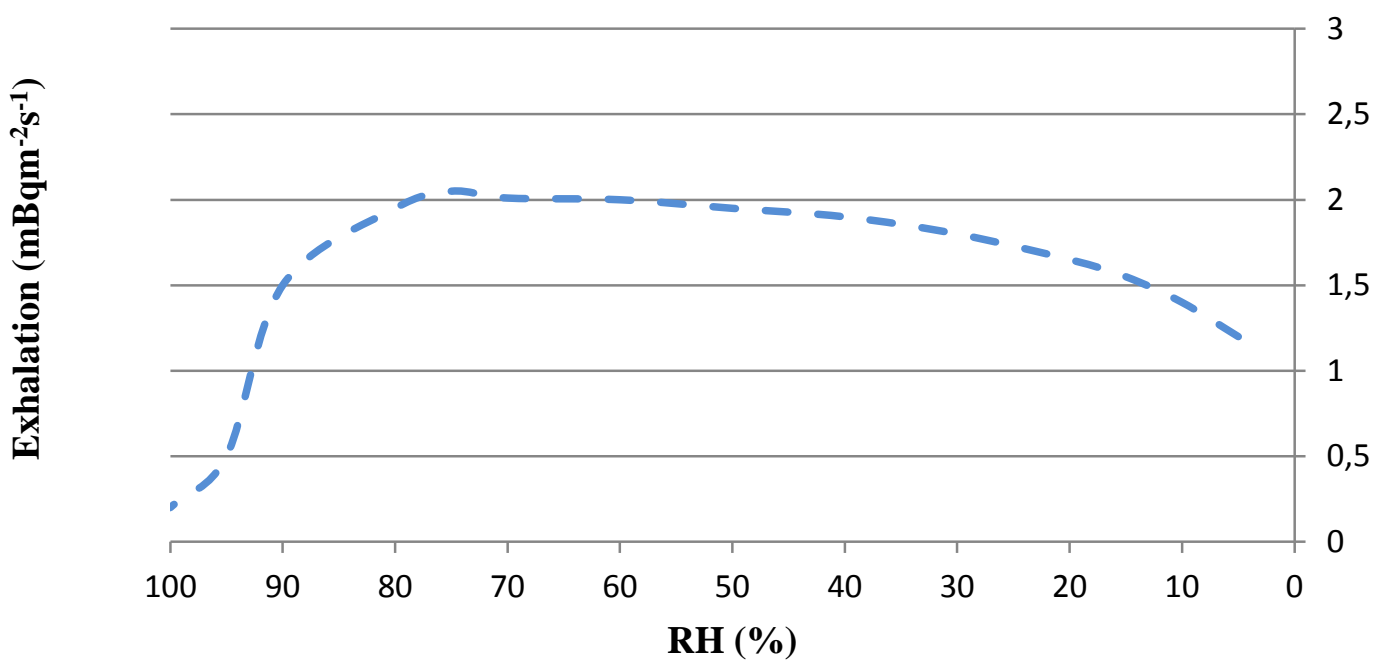

Figure 1 - The modelled curve demonstrates the very low radon exhalation rate at 100 to $90 \%$ in relative humidity, meaning, very little radon escapes from the concrete surface, when the concrete is saturated (high moisture content). Based on [11].

Accordingly, an additive, that repels water droplets (hinders free transport -clogging the pores) from the concrete surface, may also have a direct effect of the permeability or diffusion rate within the concrete [8].

Measures to reduce radon in building materials have only been studied to a minor extent.

Chauhan \& Kumar [9] showed the potentials of reducing the radon gas exhalation rates from concrete using rice husk. Also Yu et al. [12] and Taylor-Lange et al. [13] demonstrated the possible measures of reducing the exhalation rate of radon gas from different concrete surfaces using supplementary cementitious materials, such as fly ash or metakaolin.

In this research a comparison of (i) a reference concrete, (ii) a reference concrete with an addition of a liquid additive (hydrophobant) as well as, (iii) a concrete with a supplementary cementitious material (SCM) added (fly ash) are made. The corrosion inhibitor and hydrophobant, X1002 Hycrete, is directly added to the water in the concrete recipe. The fly ash used is a class $\mathrm{N}$ - fly ash originating from E-mineral in Denmark. 


\section{METHODOLOGY}

\subsection{Radon exhalation rate and radon gas measurements}

The principle makes use of a "closed system with a radon source enclosed". As radon from the concrete product builds up within a sealed aluminum container a measure of the radon exhalation rate could be calculated for the first 24 hours. The codes adopted are defined in ISO Standard 11665-7 [14].

The radon gas exhalation rate $E\left(\mathrm{~Bq} / \mathrm{m}^{2} \mathrm{~h}\right)$ is calculated knowing the initial conditions of the radon gas concentration in the "closed system" and within this project the linear regression model has been applied. The equation for the linear regression model [14] can be described as:

$$
E=\frac{\{(\mathrm{C}-\mathrm{Co}) \times V\}}{A \times t}
$$

where: $E$ = exhalation of radon gas $\left(\mathrm{Bq} / \mathrm{m}^{2} \mathrm{~h}\right), C=$ concentration of radon gas measured by the radon gas monitor $\left(\mathrm{Bq} / \mathrm{m}^{3}\right), C_{0}=$ background concentration of radon gas at initiation $\left(\mathrm{Bq} / \mathrm{m}^{3}\right), t=$ time of duration (h), $A=$ effective surface area of the sample $\left(\mathrm{m}^{2}\right), V=$ volume of the container including hoses.

The Swedish Cement and Concrete Research Institute uses an ATMOS 33 (Figure 2), which is calibrated at a yearly basis at the Swedish Radiation and Safety Authority (in Swed. Strålsäkerhetsmyndigheten). The instrument is calibrated to a predefined level of $200 \mathrm{~Bq} / \mathrm{m}^{3}$. A correction factor (F-factor) of 1.04 has been applied for all measurements.

The instrument uses an ionizing pulsation chamber, that measures the alpha decay of ${ }^{218} \mathrm{Po}$. The decay of ${ }^{218}$ Po has a distinct electric charge of $6 \mathrm{keV}$ that could be counted and converted to ${ }^{222} \mathrm{Rn}$ knowing the decay rates of ${ }^{222} \mathrm{Rn}$ and ${ }^{218} \mathrm{Po}$. Thus, the instrument displays the "radon level” in $\mathrm{Bq} / \mathrm{m}^{3}$ in its display and numerical mean values are recorded and stored every 10 minutes. Consequently, a 24 hour recorded series always contains 144 mean values used for the regression analysis. The model neglects any back diffusion of the concrete [14]. To ensure good linearity during the first 24 hours of the measurement a large volume of air in relation to the exhalation area of the concrete is used.

Calculation of radon gas in indoor air within a room is according to guidelines in the Swedish legislation, Swedish National Board of Housing, Building and Planning [15] and their references to Åkerblom \& Clavensjö [16]. Knowing the exhalation rate $(E)$ of the construction material a finalized calculation of the radon gas level within a room can be completed. The calculated radon gas level (concentration in $\mathrm{Bq} / \mathrm{kg}$ ) within a room can be described as:

$$
C m=\frac{1}{(\lambda+n)} \times \frac{E x A}{V}
$$

where, $C \mathrm{~m}=$ radon level, concentration $\left(\mathrm{Bq} / \mathrm{m}^{3}\right)$ in the room, $\lambda=$ radon decay constant, $n=$ circulations of air/hour, $E=$ exhalation rate of radon gas $\left(\mathrm{Bq} / \mathrm{m}^{2} \mathrm{~h}\right), A=$ surface of exhalation within the room $\left(\mathrm{m}^{2}\right)$ and $V=$ volume of the room $\left(\mathrm{m}^{3}\right)$. 


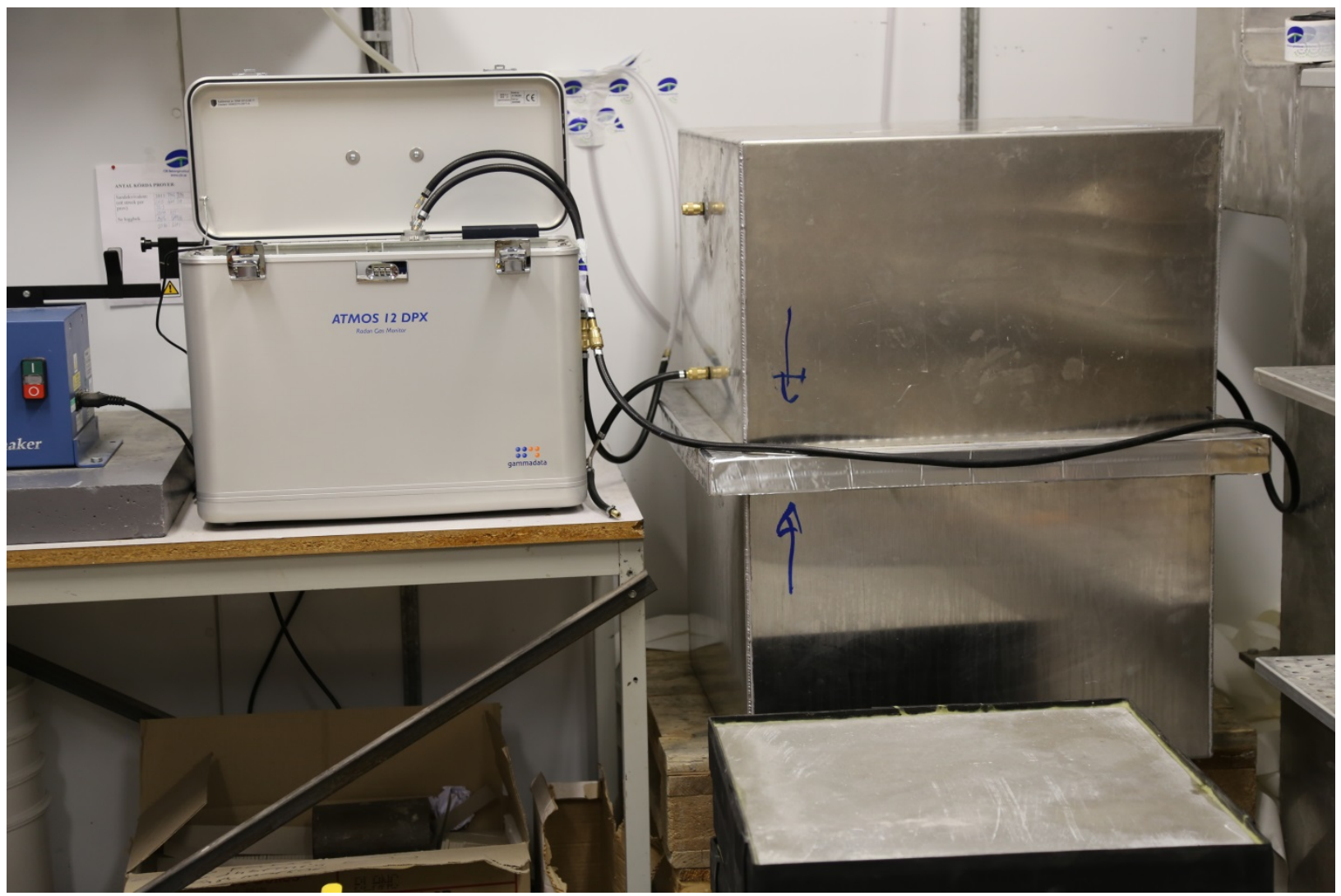

Figure 2 - The Atmos 33 (Atmos 12DPX) connected to the aluminum container. The hoses and connectors used are intended for high pressure gas flow (welding equipment). They are used as to ensure no leakage. The sealing of the containers is made with a butyl-aluminum tape that has been tested to ensure no leakage of radon.

\subsection{Assessments}

\section{Concrete recipes}

The concrete recipes contained identical constituents (aggregates, cement, water) where the only difference was (i) a contribution of an additive (Hycrete) to one recipe and, (ii) substitution of some Portland cement by fly ash (10 \% wt. of binder content) to one of the concrete recipes.

Identical concrete cubes $(150 \times 150 \times 150 \mathrm{~mm})$ were cast and after demolding the cubes were cured in a water bath for one week. The cast cubes were thereafter stored in a conditioning room at $23^{\circ} \mathrm{C}$ and $50 \% \mathrm{RH}$ between all measurements. The measurements were conducted during a 22 month period encompassing five or six separate measurements for each concrete recipe.

A standard CEM II/A-LL 42.5 R (Portland clinker cement with a portion of 6-20 \% limestone and rapid hardening properties) from the Skövde cement factory was used as binder. The component of air was set to approximately $1 \%$. A cement-content of $350 \mathrm{~kg} / \mathrm{m}^{3}$ was applied. The fly ash used originates from E-mineral (Denmark) and is categorized as B4 with fineness "N". The efficiency factor, defined as k-value, was set to 1 . 
The recipe using an additive followed the recommendations of the manufacturer. The portion used was the recommended maximum dose of $\sim 3 \%$ (vol.) of the water content. Table 1 presents the recipes and proportions used.

Table 1 - Recipes and proportions (in $\mathrm{kg} / \mathrm{m}^{3}$ and weight \%) of the different constituents in the assessed concrete specimens.

\begin{tabular}{|c|c|c|c|c|c|c|}
\hline \multirow[t]{2}{*}{ Constituents } & \multicolumn{2}{|c|}{ Standard recipe } & \multicolumn{2}{|c|}{$\begin{array}{c}\text { Standard recipe + } \\
\text { additive }\end{array}$} & \multicolumn{2}{|c|}{$\begin{array}{c}\text { Standard recipe }+ \\
\text { fly ash }\end{array}$} \\
\hline & $\mathrm{kg} / \mathrm{m}^{3}$ & $\begin{array}{c}\text { Weight } \\
(\%)\end{array}$ & $\mathrm{kg} / \mathrm{m}^{3}$ & $\begin{array}{c}\text { Weight } \\
(\%)\end{array}$ & $\mathrm{kg} / \mathrm{m}^{3}$ & $\begin{array}{c}\text { Weight } \\
\text { (\%) }\end{array}$ \\
\hline Cement, CEM II & 350 & 15.4 & 350 & 15.3 & 315 & 11.8 \\
\hline $\begin{array}{l}\text { Crushed } \\
\text { aggregate, 0/8 } \\
\text { (75 wt \%) }\end{array}$ & 1276.7 & 55.6 & 1277.7 & 56.0 & 1269.1 & 55.9 \\
\hline $\begin{array}{c}\text { Crushed } \\
\text { aggregate 8/16 } \\
\text { (25 wt \%) }\end{array}$ & 425.6 & 18.7 & 425.9 & 18.7 & 423.0 & 15.8 \\
\hline Water & 227.5 & 10.0 & 227.5 & 10.0 & 227.5 & 10.0 \\
\hline Air & $0.01(\sim 1.5 \%)$ & 0.01 & $0.01(\sim 1.5 \%)$ & 0.01 & $0.01(\sim 1.5 \%)$ & 0.01 \\
\hline $\begin{array}{c}\text { Fly Ash - class } \\
\mathrm{N}\end{array}$ & & & & & 35 & 1.3 \\
\hline $\begin{array}{l}\text { Superplasticizer } \\
\text { (sikament 56) }\end{array}$ & $\sim 0.7$ & 0.2 & $\sim 0.7$ & 0.2 & $\sim 0.7$ & 0.2 \\
\hline $\begin{array}{c}\text { Additive }^{1}, \\
\text { Hycrete X1002 }\end{array}$ & - & & 10.5 & 2 & & - \\
\hline Total & 2280.1 & & 2281.4 & & 2269.9 & \\
\hline w/c ratio & 0.65 & & 0.65 & & 0.65 & \\
\hline
\end{tabular}

1 The additives sikament 56 and Hycrete X1002 are presented as “\%” of cement binder weight.

\section{Relative Humidity}

Measurements were made using equipment from Vaisala Oy named Vaisala HM44. The equipment uses the variation in electric potential in the air due to the actual moisture content within the air (difference in conductivity) at a steady state temperature. A calibration kit, designed HMK 15 aided as to ensure limited drifting of the probes. The salts, $\mathrm{LiCl}$ and $\mathrm{K}_{2} \mathrm{SO}_{4}$, were chosen as to encompass the full span of relative humidity (11 to $98 \%$ in $\mathrm{RH}$ at 
approximately $20^{\circ} \mathrm{C}$ ). Using calibration tables from Greenspan [17] an uncertainty less than 1.5 $\%$ was calculated for the probes before the first measurements were initiated.

The procedure to assess the relative humidity within the concrete could be defined as (i) a hole of $15 \mathrm{~mm}$ in diameter and $50 \mathrm{~mm}$ depth was drilled in each concrete cube 10 days after casting, (ii) black plastic tubes (hollow inside) were inserted into the drilled holes, (iii) a sealing epoxy were added between outside of plastic tubes and the concrete to ensure no leakage of air.

The measurements were conducted by inserting the probe inside the plastic tube and sealing it with a rubber gasket at the top (Figure 3). The probes were fixed in place for at least two days before the measurements were commenced according to recommendations [18]. The first measurements were made approximately two weeks after the concrete specimens were cast.

A supplementary control task was also conducted. The concrete specimens were also weighed within one day after measurement of their respective readings of the RH (Figures 4 and 5). This was conducted as to ensure that the measured relative humidity of the concrete specimens provided reasonably reliable values.

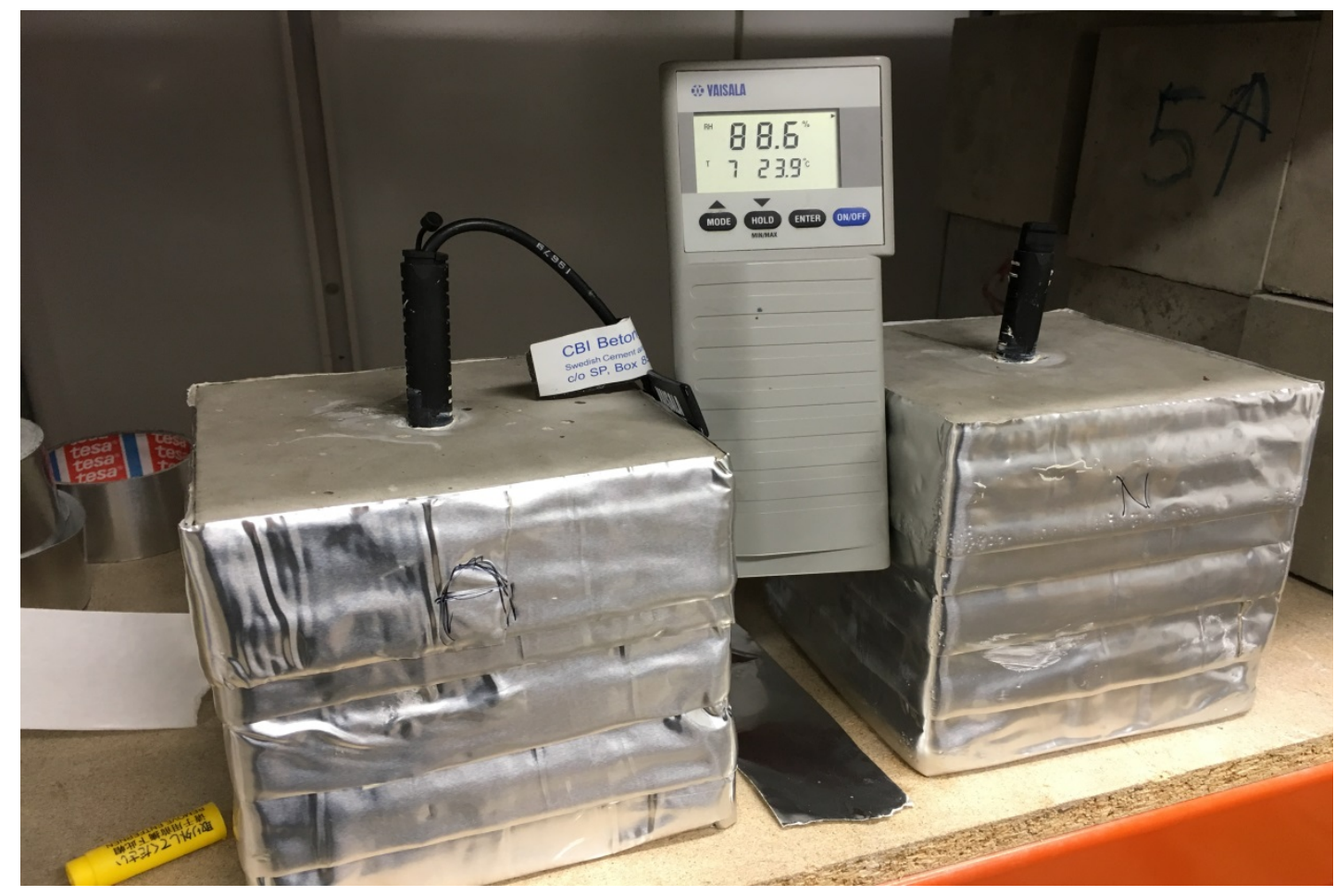

Figure 3 - Two of the three investigated concrete cubes (150 X 150 X $150 \mathrm{~mm}$ ) sealed with aluminum tape on each side except the top. The figure also shows the plastic tubes on top as to measure the relative humidity. The current reading is $88.6 \%$ in relative humidity using probe 7 at $23.9^{\circ} \mathrm{C}$ for the recipe containing an additive. 
Nordic Concrete Research - Publ. No. NCR 58 - ISSUE 1 / 2018 - Article 2, pp. 17-34

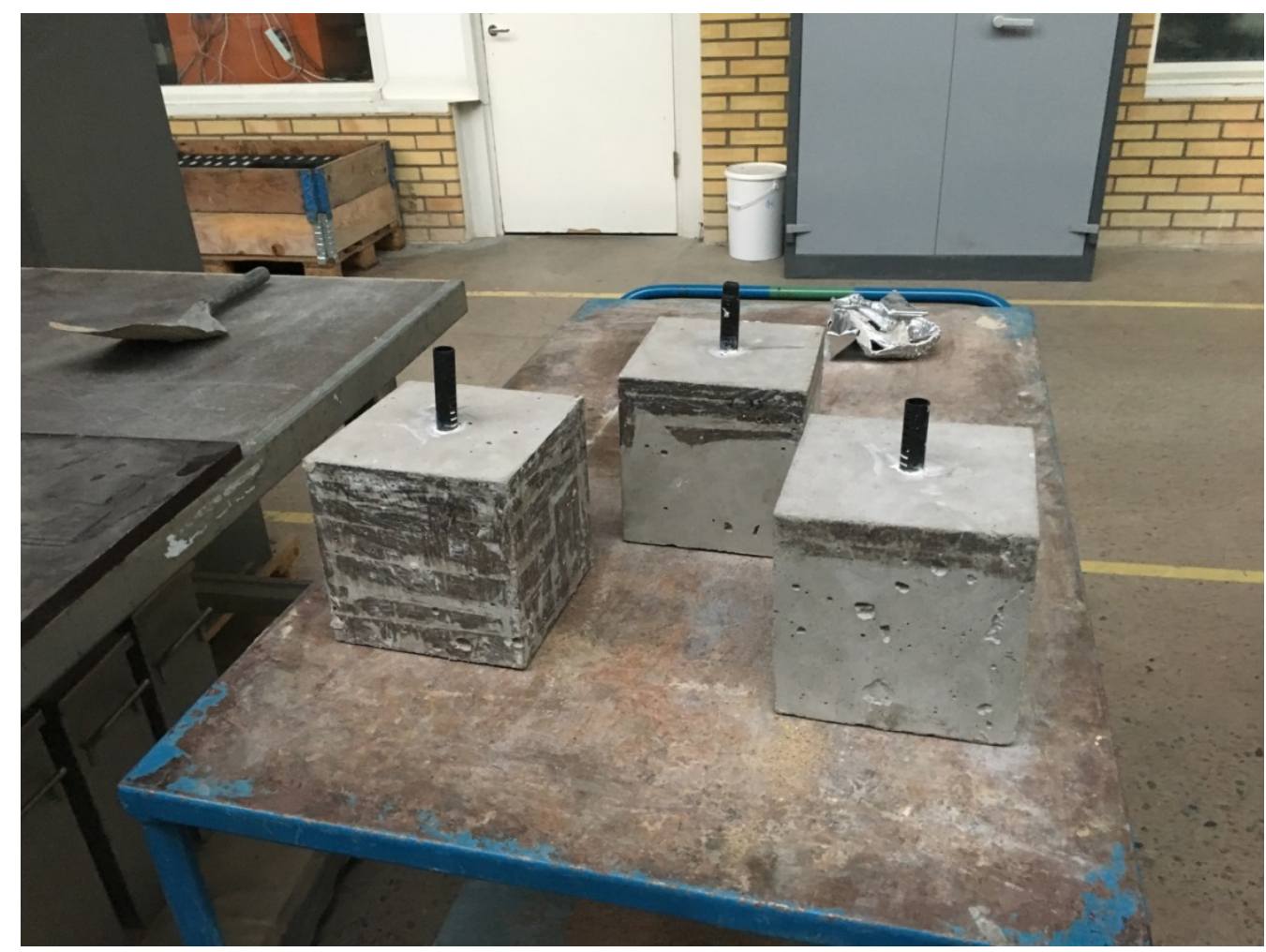

Figure 4 - The investigated concrete cubes resting on a carriage before measurement of their respective weight.

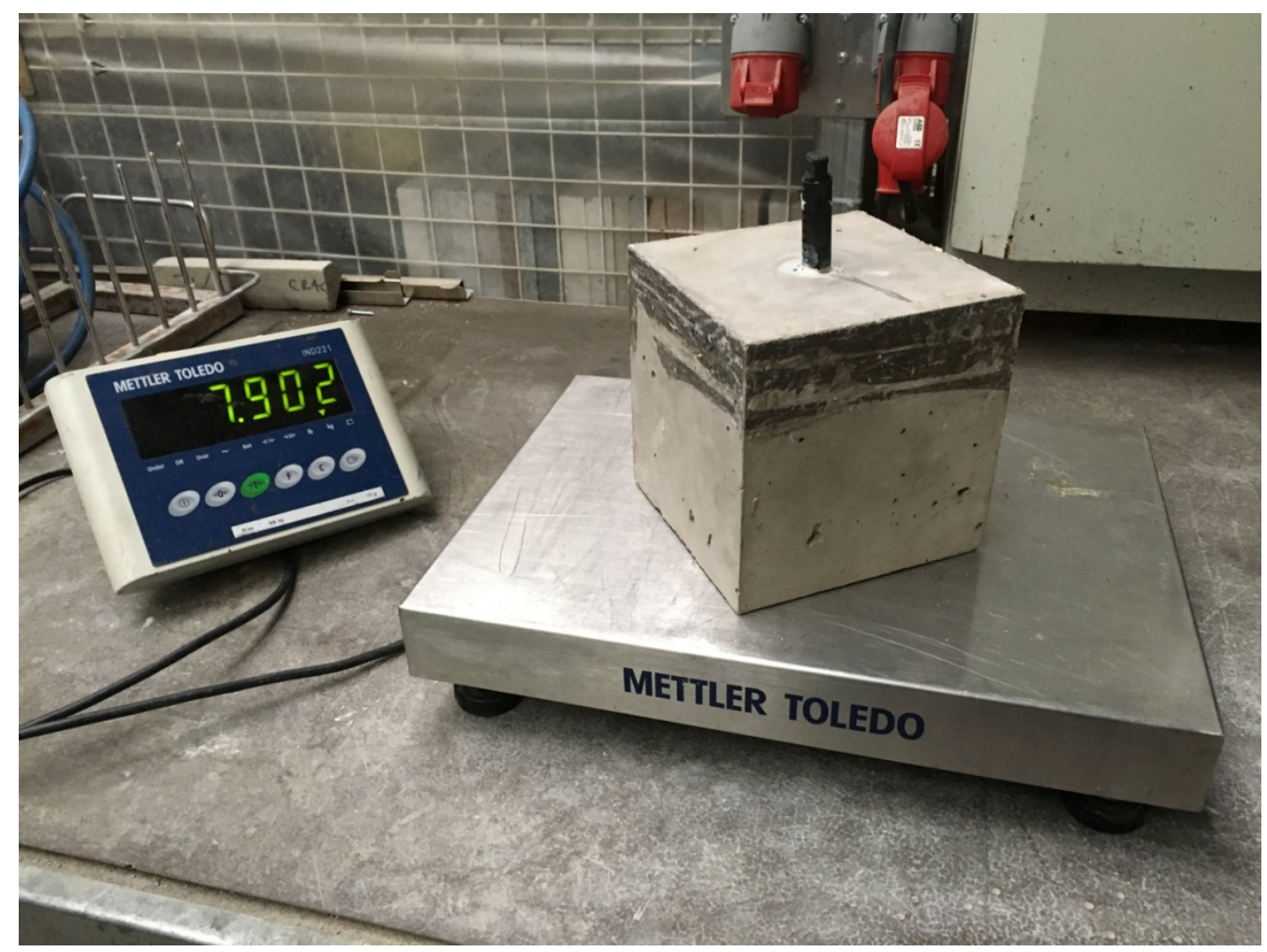

Figure 5 - Measurement of weight for one of the cast cubes. The same calibrated scalar from MettlerToledo was used for each weight measurement. 


\section{RESULTS}

Figure 6 presents the measured radon exhalation rate of the three concrete recipes investigated as a function of time. The included error bars $( \pm 5 \%)$ originate from repetition measurements performed by Döse et al. [19] for similar recipes with the same w/c-ratio. The relative humidity as a function of time for each concrete cube investigated is also shown in Figure 7. A slight difference in their relative humidity could be observed after 22 months.

A distinct difference in exhalation rate between a standard recipe and a recipe using an additive or SCM is in general evident. An overall gross reduction of $\sim 30-35 \%$ in the exhalation rate $\left(\mathrm{Bq} / \mathrm{m}^{2} \mathrm{~h}\right)$ using an additive or SCM could be estimated for $\mathrm{RH}$ lower than 85-80 \% (Figure 8)

But, the results of each concrete recipe are jittery and far from linear, particularly for readings were the relative humidity is high ( $>80-85 \% \mathrm{RH})$. However, in each measurement series a fairly low initial radon exhalation value is followed by a maximum. This is clearly evident in Figure 8 where the radon exhalation rate of the three concrete recipes investigated is presented as a function of the relative humidity.

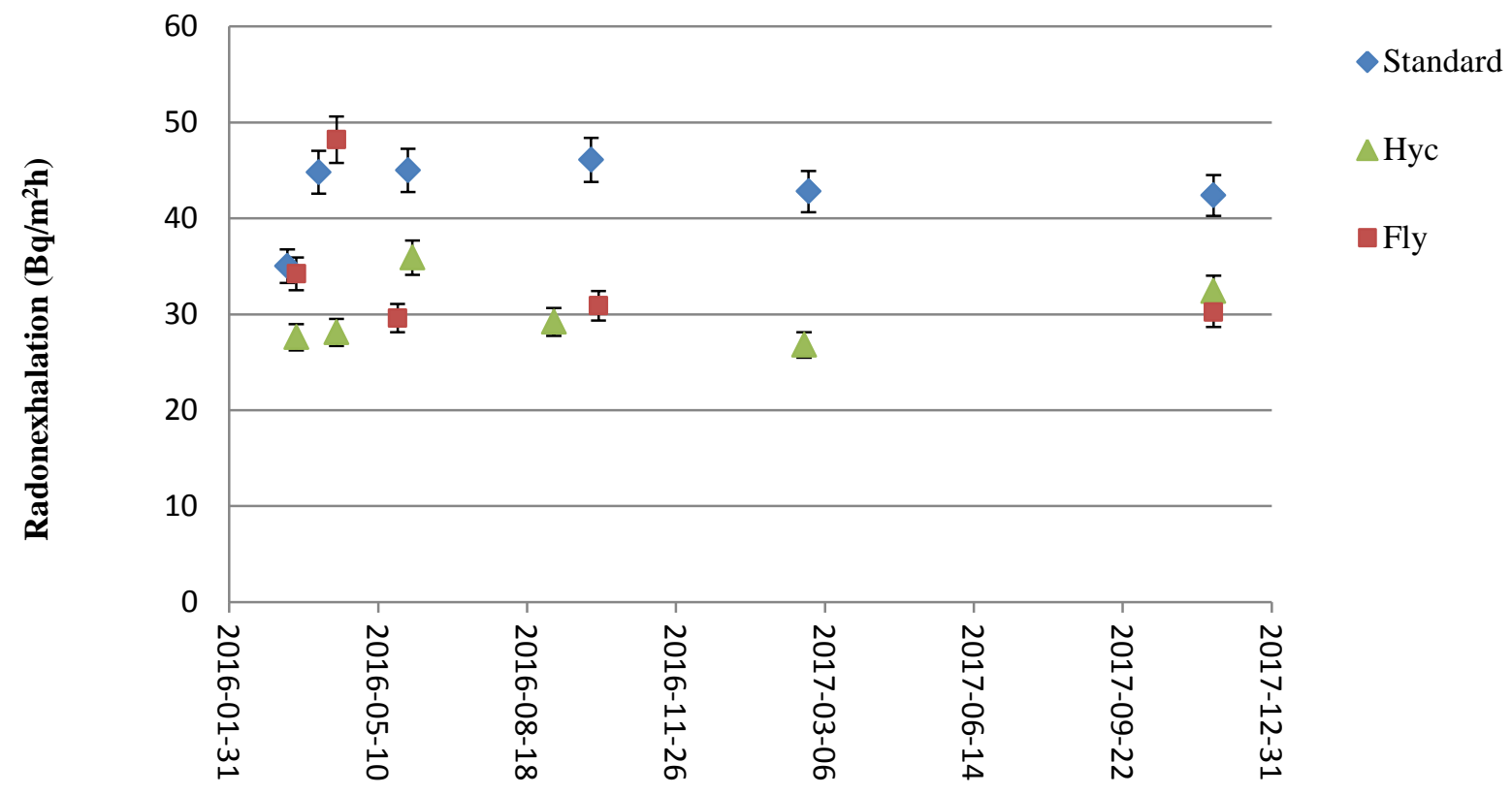

Figure 6 - The radon exhalation rate as a function of time (date) of the concrete recipe investigated. The error bars are $\pm 5 \%$ [19]. 
Nordic Concrete Research - Publ. No. NCR 58 - ISSUE 1 / 2018 - Article 2, pp. 17-34

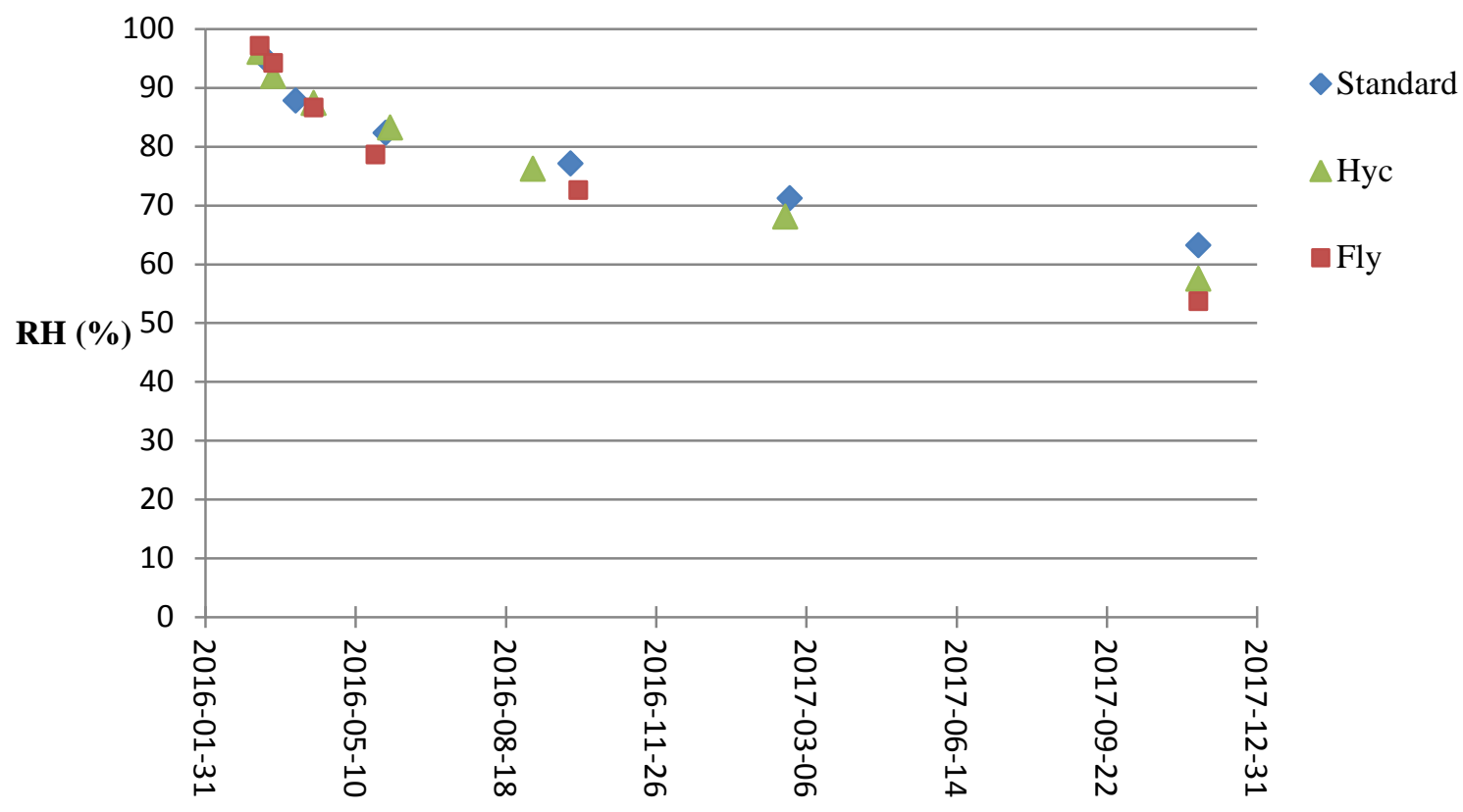

Figure 7 - The relative humidity as a function of time (date) for each concrete sample investigated.

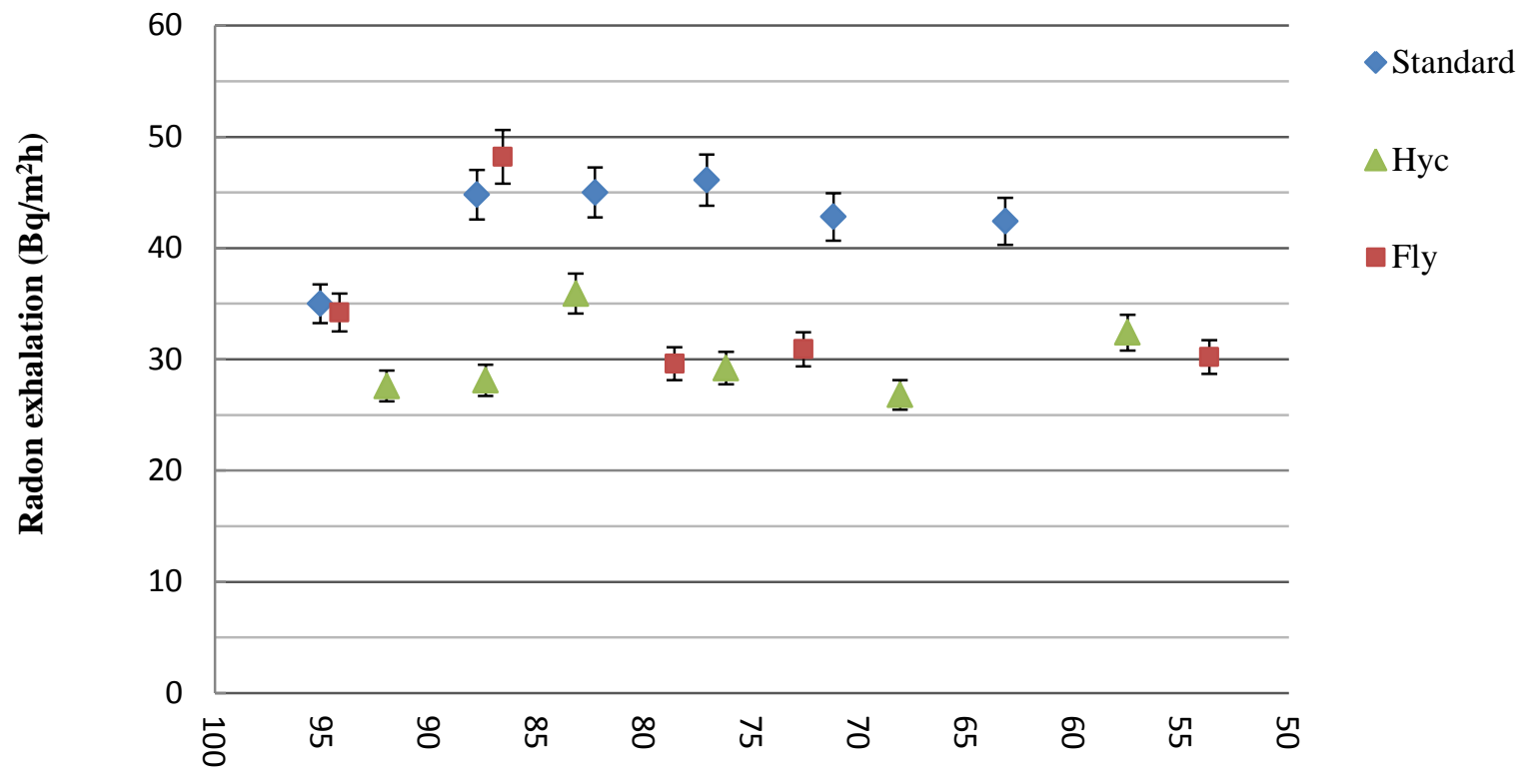

Relative Humidity, RH (\%)

Figure 8 - The radon exhalation rate as a function of $R H$ of the concrete samples investigated. 
Control measurements of the concrete cubes' masses were performed throughout the study. In Table 2, the measured initial length of the sides of the cubes, their initial and final masses and calculated volumes and densities are tabulated.

Table 2 - The initial and final mass, length of the cast cubes and their respective volume and density.

\begin{tabular}{|c|c|c|c|c|c|c|c|c|}
\hline \multirow[t]{3}{*}{ Recipe } & \multirow{3}{*}{$\begin{array}{c}\text { Mass, } \\
\text { initial } \\
\text { (kg) }\end{array}$} & \multirow{3}{*}{$\begin{array}{l}\text { Mass, } \\
\text { final } \\
(\mathrm{kg})\end{array}$} & \multirow{3}{*}{$\begin{array}{c}\text { Mass, loss } \\
\text { (kg) }\end{array}$} & \multicolumn{3}{|c|}{ Length of sides of cubes } & \multirow[t]{2}{*}{ Volume } & \multirow[t]{2}{*}{ Density } \\
\hline & & & & $A$ & $B$ & C & & \\
\hline & & & & & (m) & & $\left(\mathrm{m}^{3}\right)$ & $\left(\mathrm{kg} / \mathrm{m}^{3}\right)$ \\
\hline Fly Ash & 7.368 & 7.238 & 0.130 & 0.150 & 0.150 & 0.149 & 0.0033 & 2201 \\
\hline Standard & 8.016 & 7.911 & 0.105 & 0.149 & 0.151 & 0.151 & 0.0034 & 2378 \\
\hline Hycrete & 8.010 & 7.902 & 0.108 & 0.150 & 0.151 & 0.151 & 0.0034 & 2340 \\
\hline
\end{tabular}

Noticeably, the density of the concrete recipe containing fly ash is markedly lower than the densities of the other two recipes (Table 2). The other recipes also have slightly higher densities than designed. It is also apparent that the loss of water (mass) seemingly is greater for the recipe containing fly ash. In Figure 9 the density correction as the mass decrease during hydration for each recipe is shown. In Figure 10 the mass as a function of the relative humidity is presented. Using a polynomial function of 2nd order a strong $\mathrm{r}^{2}$-value can be demonstrated.

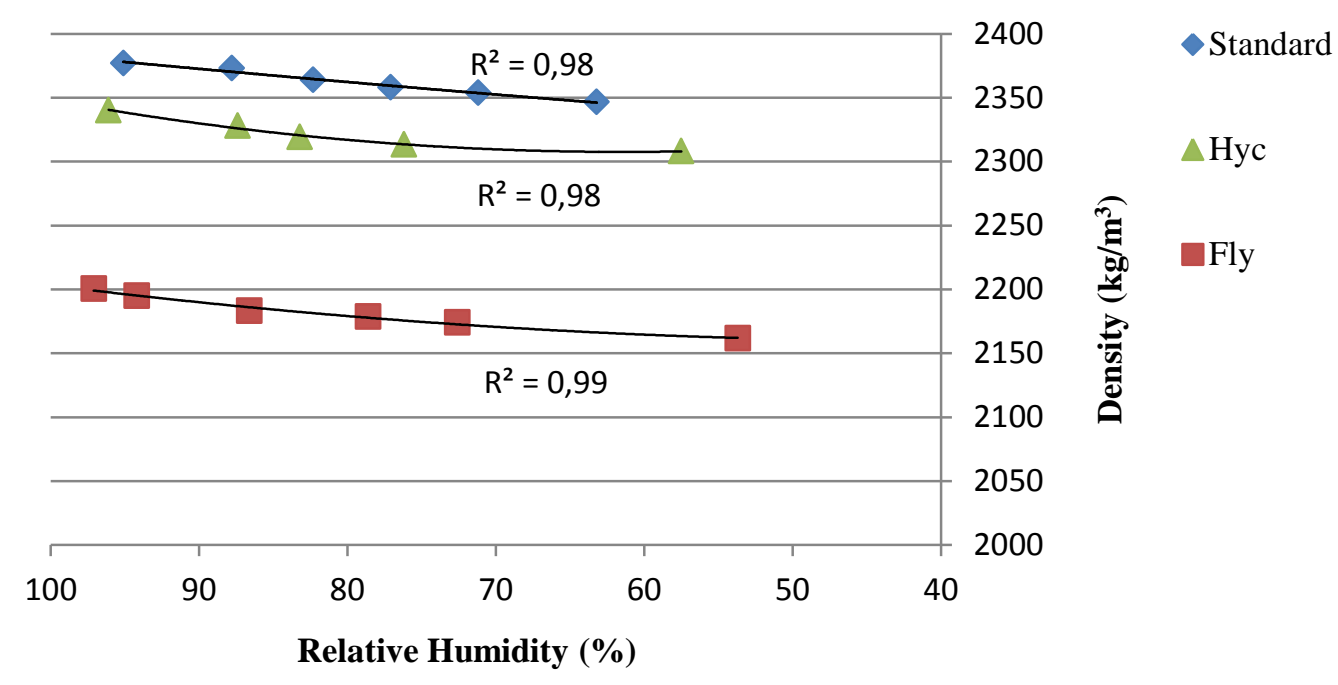

Figure 9 - The density of the concrete cubes as a function of the relative humidity for the three concrete cubes investigated. 


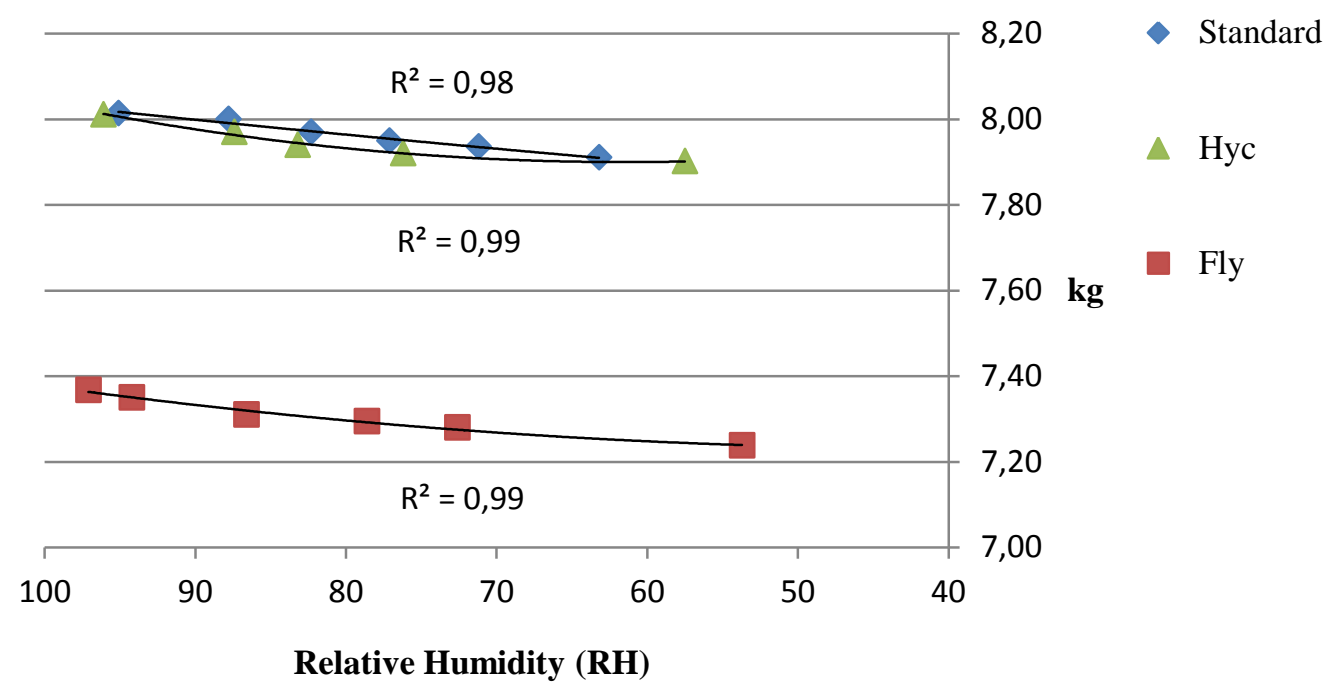

Figure 10 - The mass of the concrete cubes as a function of the relative humidity for the three concrete cubes investigated.

Figures 6 and 8 give an indication of a strong variation of the exhalation rate, especially the concrete recipe containing fly ash, at $\mathrm{RH}$ values $>85 \%$. Seemingly a more reliable estimate of the mean radon exhalation rate could be achieved at $\mathrm{RH}$ values $<85-80 \%$. In Table 3 , the exhalation rates for each concrete recipe and their ratios (difference) in percent (\%) in relation to the standard recipe are presented.

Table 3 - The exhalation rates of the different concrete recipes and their ratios in relation to the standard recipe.

\begin{tabular}{ccccccc}
\hline Date & $\begin{array}{c}\text { RH- } \\
\text { Standard } \\
\text { recipe } \\
(\mathrm{RH})\end{array}$ & $\begin{array}{c}\text { Radon } \\
\text { exhalation - } \\
\text { Standard } \\
\left(\mathrm{Bqh} / \mathrm{m}^{2}\right)\end{array}$ & $\begin{array}{c}\text { Radon } \\
\text { exhalation - } \\
\text { Fly ash } \\
\left(\mathrm{Bqh} / \mathrm{m}^{2}\right)\end{array}$ & $\begin{array}{c}\text { Radon } \\
\text { exhalation - } \\
\text { Hycrete } \\
\left(\mathrm{Bqh} / \mathrm{m}^{2}\right)\end{array}$ & $\begin{array}{c}\text { Difference in } \\
\text { radon } \\
\text { exhalation } \\
\text { rate }(\%) \text { - Fly } \\
\text { ash/ Standard }\end{array}$ & $\begin{array}{c}\text { Difference in } \\
\text { radon } \\
\text { exhalation rate } \\
\text { Standard }\end{array}$ \\
\hline $2016-03-10^{1}$ & 95.1 & 35 & 34 & 28 & 0.98 & 0.79 \\
$2016-04-06^{1}$ & 87.8 & 45 & 48 & 28 & 1.08 & 0.63 \\
$2016-05-30^{1}$ & 82.3 & 45 & 30 & 36 & 0.67 & 0.80 \\
$2016-09-20^{2}$ & 77.1 & 46 & 31 & 29 & 0.67 & 0.63 \\
$2017-02-22^{1}$ & 71.2 & 43 & - & 27 & - & 0.63 \\
$2017-11-22^{1}$ & 63.2 & 42 & 30 & 32 & 0.71 & 0.76
\end{tabular}

${ }^{1}$ Measurements of each recipe performed \pm one week ${ }^{2} \cdot$ Measurements of each recipe performed \pm two weeks. 


\section{DISCUSSION}

The irregular pattern of radon exhalation rates displayed during the hydration process of in particular the recipe containing fly ash and in part the recipe containing a bulk additive (liquid) may have a sound explanation. For all recipes the initial (first) values measured had an RH in the interval 90-96 \%. This is of interest in relation to the study made by Cozmuta et al. [11] where the exhalation rate for values in the range of $100-90 \%$ in $\mathrm{RH}$ were modelled to be very low to moderate. This phenomenon is due to radon gas almost not being permeable in a water filled pore structure $[11,12]$ compared to air filled voids. The maximum levels of radon exhalation according to their study [11] were also in the range of an $\mathrm{RH}$ of $85-80 \%$. This seemingly corresponds satisfactorily to the current study. The reference concrete (Figure 7), in part, manifests their modelled behavior of the exhalation rate at different RH.

The difference in densities between the recipes could not be pleasingly explained. The standard recipe as well as the recipe containing fly ash deviates more than expected. The higher degree of evaporation of water (Table 2) of the fly ash recipe, however, may imply an added excess of water compared to the designed recipe that may in part explain the low w/c ratio. The difference in the measured densities between the standard recipe and the fly ash accounts for $\sim 7 \%$ wt. Radon exhalation is influenced by the density of a material and a material's density is proportional to the energy quantity "stopping power" [20], that could be defined as,

$$
S=d E / d x
$$

where $S$ = stopping power $(\mathrm{Mev} / \mathrm{cm}), d E$ is energy loss per traveled distance and $d x$ is traveled distance

However, it is beyond the scope of this article to further elaborate on the density influence, but for concretes with a rather small difference between densities, the influence upon exhalation rate is considered negligible. For a deeper understanding the reader is advised to Isaksson \& Rääf [21]. But, in short, an increased density yields a higher stopping power $(\mathrm{MeV} / \mathrm{cm})$ within a material (concrete), resulting in less radon being able to escape to the surface of a material. Consequently, if densities were set equal (as they were supposed to), the resulting radon exhalation difference between the investigated recipes would be even larger, than presented within this study. Significantly, and in view of the results, it could be seen that parameters, such as a materials permeability and porosity, hence have a much more substantial impact then the density difference observed between the concrete recipes.

The strong fluctuations of the radon exhalation rate at specifically, higher RH-values, are likely due to high initial porosities and loose pore structure of the concrete specimens in their initial stages of hydration. This favors a high transport rate [12]. This hypothesis is clearly demonstrated by Zhuqing \& Guang [22], who through tests on cement pastes compared reference cement with admixtures containing fly ash during a two year period. This should be emphasized, especially for the binder mix containing fly ash (SCM), where the puzzolanic effect needs to initiate before a more consistent pore structure of the concrete is defined. This may explain the initial high values of the radon exhalation rate of the recipe containing fly ash.

De Jong [8] reported that an addition of fly ash in general reduces the general pore size, which is consistent with findings by Zhuqing \& Guang [22], where the relative critical pore size of cement paste blended with fly ash is smaller than for reference cement paste after 90 days of curing and onwards. Setina et al. [23] reported similar conclusions where the use of micro silica 
as a SCM reduced the total pore volume and also an overall smaller pore size compared to a reference concrete. Based on a series of experiments, also Keller et al. [24] reported that the use of fly ash gives a more dense concrete (better degree of compaction) and that the reduced pore size reduced the overall permeability of the concrete specimens. A decrease of the average pore size reduces the inter-connectivity between the pores and the permeability as a result. The current study seemingly supports this concept.

It is also the authors' belief that the rather small differences (in $\mathrm{kg}$ ) in the input of aggregates between the concrete recipes should not have any remarkable influence upon the radon exhalation rate. Nor the substitutions of some fly ash instead of Portland cement. Even though the largest contribution of radium-226 and consequently radon resides from the aggregates, the minor difference between the recipes would not generate any significant change in the overall uranium (parent atom of radon production) content of the concrete cubes cast.

The liquid additive, Hycrete X1002, is a bulk additive that contains alkali-metal ions (sodium or potassium) in combination with carboxylic acid groups and polysiloxane constituents [25]. The product is protected by several US-patents [26-31]. Then general concept of bonding of a silane or polysiloxane to the concrete surface is in text and figures eminently explained by Selander in his doctoral thesis [32]. The initial key is to create a covalent bond of an inorganic substance to an organic. In brief, the hycrete bulk additive is added to the water, initiating a three stage process; (i) hydrolysis, followed by (ii) condensation and (iii) bonding [33]. In this process the alkoxy groups of the polysiloxanes generate a thin film (hydrophobic film) [33] that will swiftly bond to the cement, calcium-silicate hydrates (C-S-H) or aggregate surfaces. The carboxyl acid group $(\mathrm{R}-\mathrm{COOH})$ is strongly attracted to calcium at any surface, and the polymer (hydrophobic part) will subsequently position itself in close proximity to the surface [34]. This bonding with cement, or C-S-H or aggregate leads in turn to a reduced free transport of water and reduced breathability [33, 34] and hence also a reduced water absorption [34, 35]. The "hydrophobic film" acts in part as an impermeable layer [33]. This is caused by the large differences in surface tension of water and silicones (72 $\mathrm{mN}^{\circ} \times \mathrm{m}^{-1}$ and $22 \mathrm{mN} \times \mathrm{m}^{-1}$, respectively) and thus water cannot penetrate the film easily. However, as mentioned, the pore structure is still open, but with a lower diffusion coefficient [33].

V. Spaeth et al. [35] showed in experiments that this immediate contribution of a bulk additive as a result also delays the hydration of the C-S-H linkage. Selander et al. [34] demonstrated in a study with shotcrete the effect of adding a hydrophic additive. The capillary absorption of the tested hydrophobic specimen with a w/c ratio of 0.55 was reduced by $85 \%$ in relation to the reference concrete. Consequently, it is likely that the use of a hydrophobic product strongly reduces the diffusion length $L$ of radon and less radon is able to reach the surface per unit time. As earlier described the diffusion length will consequently be much lower, indicating that only a part of the radon contained within the concrete cubes is able to reach the surface before it decays. In some recent experiments by Chauhan and Kumar [36], a concrete series using ordinary Portland cement with a w/c ratio of 0.45 , and containing different additions of micro silica showed an interval of $0,02-0,13 \mathrm{~m}$ in radon diffusion length [36]. Meaning, most of the radon within the investigated cubes of this study would have been expected to contribute to the radon exhalation at the surface.

Though, the primary intent of the study was to investigate, whereas any differences could be observed in radon exhalation rate of three different concrete recipes, the study was not 
thoroughly prepared. The lack of more study material (several concrete cubes of each recipe) in part hindered further examination of the diffusion rates of the concrete recipes or control measurements of the compressive strength of each material.

Secondly, since only one concrete cube of each recipe was studied, this statistically causes a relatively large uncertainty. Thus, further testing is emphasized and should be carried out before any definitive conclusions can be drawn. Nevertheless, a distinct trend in exhalation rate between the different recipes is noticeable for concrete specimens with a $\mathrm{RH}<80-85 \%$.

Finally, the measurements depth for the RH may be addressed. The readings were made $50 \mathrm{~mm}$ into the concrete samples. This of course, does not reflect the relativity humidity on the top surface, nor the core of the concrete cubes. The depth was chosen to be at least $50 \mathrm{~mm}$ into the concrete, to ensure reliable readings. Most certainly, the surface of the concrete will display slightly lower RH-values.

\section{CONCLUDING REMARKS}

In the current study it has been demonstrated a reduction of $\sim 30-35 \%$ of radon gas exhalation rate from concrete specimens using a liquid additive (Hycrete, X1002) or a SCM (fly ash) at relative humidity's $<80-85 \%$. The use of SCM as a binder, also serves a mean to lower the overall use of Portland cement worldwide. This at the end generates a positive impact from an environmental aspect.

The effect of using a liquid additive or a SCM-material may have a strong impact on the radon gas exhalation rate of concrete and consequently the radon gas level within a room. Chauhan \& Kumar [9, 36] demonstrated a similar effect using an alternative material such as rice husk and micro silica in different concrete recipes.

The reduction of radon exhalation rates also reduces the effective dose received by human beings. Using guidelines of ICRP [37], the reduction is equivalent to $\sim 1.5-2 \mathrm{mSv}$ per year. This is in relation to the reference value of the normal concrete specimen investigated and relates to the European reference room [38] where all walls, tile and floor are made of concrete.

The results demonstrate the significance and effectiveness of an additive and a supplementary cementitious material as an aid in reducing radon levels in building materials. Consequently, these material choices may be an optional way as to further limit the exhalation of radon. Further and more comprehensive studies are needed as to confirm and validate the initial assessments. Current studies are ongoing including several other liquid additives and supplementary cementitious materials in order to verify the initial results.

\section{ACKNOWLEDGEMENTS}

Special thanks to the Swedish Consortium for Financing Fundamental Research in the Concrete Area who has partly funded the research in the concrete area. Special thanks also to my colleagues at RISE CBI Betonginstitutet with guidance on the concrete castings produced. 
Nordic Concrete Research - Publ. No. NCR 58 - ISSUE 1 / 2018 - Article 2, pp. 17-34

\section{REFERENCES}

1. World Health Organization. "WHO Handbook on Indoor Radon: a Public Health Perspective,” World Health Organization, Geneva, Switzerland, 2009, 110 pp.

2. EC. "CPR - Regulation (EU) no 305/2011 of the European Parliament and of the Council Laying Down Harmonized Conditions for the Marketing of Construction Products and repealing,” Council Directive 89/106/EEC, Official Journal European Union, Vol. 88, 2011, pp. 5-43.

3. EC. “Council Directive 2013/59/Euroatom of 5 December 2013 Laying Down Basic Safety Standards for Protection against the Dangers Arising from Exposure to Ionizing Radiation, and repealing Directives 89/618/Euroatom, 90/641/Euroatom, 96/29/Euroatom, 97/43/Euroatom and 2003/122/Euroatom,” Offical Journal of the European Union, Vol. 13, 2014, 73 pp.

4. Darby S, Hill D, Auvinen A, Barros-Dios JM, Baysson H, Bochicchio F, Deo H, Falk R, Forastiere F, Hakam M, Heid I, Kreienbrock L, Kreuzer M, Lagrade F, Mäkeläinen I, Muirhead C, Oberaigner W, Pershagen G, Ruano-Ravina A, Ruosteenoja E, Schaffrath Rosario A, Tirmarche M, Tomasek L, Whitley E, Wichmann H-E \& Doll R: "Residential Radon and Lung Cancer: Detailed Results of a Collaborative Analysis of Individual Data on 7148 Persons with Lung Cancer, 14208 Persons without Lung Cancer from 13 Epidemiologic studies in Europed," Scandinavian Journal of Work, Environment and Health, Vol. 32, 2006.

5. Mjönes L, Burén A, Swedjemark G A: "Radon Rates in Swedish Dwellings (Radonhalter i svenska bostäder),” SSI-report-a 84-23”, Stockholm, Sweden, 1984, 56 pp. (In Swedish).

6. Jelinek C \& Eliasson T: "Radiation from Bedrock (Strålning från bergmaterial)," Geological Survey of Sweden, SGU-report 2015:34, Uppsala, Sweden, 2015, 26 pp. (In Swedish).

7. Stranden E, Kolstad A. K., Lind B: "The Influence of Moisture and Temperature on Radon Exhalation,” Radiation Protection Dosimetry, Vol. 7, No 1-4, 1984, pp. 55-58.

8. De Jong P \& van Dijk W: "The Effect of the Composition and Production Process of Concrete on the ${ }^{222} \mathrm{Rn}$ Exhalation Rate,” Environmental International, Vol. 22, 1996, pp. 287-293.

9. Chauhan R P \& Kumar A: "Radon Resistant Potential of Concrete Manufactured Using Ordinary Portland Cement Blended with Rice Husk Ash,” Atmospheric Environment, Vol. 81, 2013, pp. 413-420.

10. Zhongnan S, Xiao X, Yanwen L, Jingna Y, Zhongyu H, Shizhao S, Lihong J, Weidong Z, Lijin X, Hongqiang Z, Jian Q, Wenzhan J, Tao Z, Liang H, Baohua W, Xiqiang L \& Nan Z: "Experimental Exploration of the Waterproofing Mechanism of Inorganic Sodium Silicate-Based Concrete Sealers,” Construction and Building Materials, Vol. 104, 2016, pp. 276-283.

11. Cozmuta I, Van der Graaf E R \& de Meijer R J: "Moisture Dependence of Radon Transport in Concrete: Measurements and Modeling," Health Physics, Vol. 85, No. 4, 2003, Groningen, The Netherlands, pp. 438-456.

12. Yu K N, Young E C M, Stokes M J, Kwan M K \& Balendran R V: "Radon Emanation from Concrete Surfaces and the Effect of the Curing Period, Pulverized Fuel Ash (PFA) Substitution and Age,” Applied Radiation and Isotopes, Vol. 48, No 7, 1997, pp. 10031007.

13. Taylor-Lange S C, Stewart J G, Juenger M C G \& Siegel J A: "The Contribution of Fly Ash toward Indoor Radon Pollution from Concrete,” Building and Environment, Vol. 56, 2012, pp. 276-282. 
14. ISO 11665-7. "Measurement of Radioactivity in the Environment - Air: Radon-222 Part 7: Accumulation Method for Estimating Surface Exhalation Rate," International Standard (ISO), First edition, Geneva, Switzerland, 2012, 23 pp.

15. Swedish National Board of Housing, Building and Planning: "The National Board of Housing, Building and Planning Regulatory Framework (Boverkets författningssamling),” BFS 2006:12 - BBR 12 (in Swedish), Karlskrona, Sweden, 2006, 44 pp. (In Swedish).

16. Åkerblom G \& Clavensjö B: "Book of Radon - Preventing Measures in New Buildings (Radonboken, förebyggande åtgärder i nya byggnader).” Formas, Stockholm, Sweden, 2004, 106 pp. (In Swedish).

17. Greenspan L: "Humidity Fixed Points of Binary Saturated Aqueous Solutions". Journal of Research of the National Bureau of Standards. A Physics and Chemistry, Vol. 81a, No 1, 1977, pp. 89-95.

18. Åhs, M. "Simulation of Moisture Measurements in Concrete with a Low w/c Ratio (Simulering av fuktmätning i betong med lågt vct),” TVBM; Div. of Building Materials, Faculty of Engineering, Lund University, Lund, Sweden, Vol. 3177, 2014, 46 pp. (In Swedish).

19. Döse M: "Ionizing Radiation in Concrete and Concrete Buildings - Empirical Assessment," Bulletin 141, (Licentiate Thesis), Dept. of Civil and Architectural Engineering, School of Architecture and Built Environment, KTH Royal Institute of Technology, Stockholm, Sweden, 2016, 91 pp.

20. Isaksson M: "Basic Radiation Physics (Grundläggande strålningsfysik)", $2^{\text {nd }}$ edition. Elanders, Studentlitteratur, Lund, Sweden, 2011, 330 pp.

21. Isaksson M \& Rääf, C L: "Environmental Radioactivity and Emergency Preparedness," CRC Press, Taylor \& Francis Group, Florida, USA, 2016, 614 pp.

22. Zhuqing Y \& Guang Y: "The Pore Structure of Cement Paste Blended with Fly Ash," Construction and Building Materials, Vol. 45, 2013, pp. 30-35.

23. Setina J, Gabrene A \& Juhnevica I: "Effect of Pozzolanic Additives on Structure and Chemical Durability of Concrete,” Procedia Engineering, Vol. 57, 2013, pp. 1005-1012.

24. Keller G, Hoffmann B, \& Feigenspan T: "Radon Permeability and Radon Exhalation of Building Materials,” Science of the Total Environment, Vol. 272, 2001, pp. 85-89.

25. Hycrete Inc.: "Material Safety data Sheet Hycrete X1002.”. Hycrete Inc., p 3. www.hycrete.com

26. US-Patent 7261923. 2003. “Alkali Salt of Branched Dioic Acid and Defoamer; Post Surface Treating Construction Materials; Imparting Lasting, Effective Moisture Resistance".

27. US-Patent 7381252. 2003. “Anti-Corrosion Admixture Composition for Concrete Compositions for Use in Reinforced Concrete Structures”.

28. US-Patent 7407535. 2006. “Compositions Containing a Disodium or Dipotassium C9-15 Branched Alken-1-Ylsuccinate for Treating Formed Concrete Structures; Despite Being Water Soluble the Treatments Deliver Improved Moisture Resistance”.

29. US-Patent 7498090. 2003. “A Material Such as Reinforced or Unreinforced Concrete Coated with a Disodium or Dipotassium Salt of an Unsaturated Dicarboxylic Acid, Such as Disodium Dodecenylsuccinate".

30. US-Patent 7513948. 2006. “Autogenous Healing of Cracks in Concrete Structures”.

31. US-Patent 7670415. 2007. "Vapor Barrier for Porous Structures and System”.

32. Selander, A, "Hydrophobic Impregnation of Concrete Structures - Effects on Concrete Properties," Bulletin 141 (Doctoral Thesis), Dept. of Civil and Architectural Engineering, School of Architecture and Built Environment, KTH Royal Institute of Technology, Stockholm, Sweden, 2010, 45 pp. 
Nordic Concrete Research - Publ. No. NCR 58 - ISSUE 1 / 2018 - Article 2, pp. 17-34

33. Roos M, König F, Stadtmüller S \& Weyershausen B: “Evolution of Silicone Based Water Repellents for Modern Building Protection,” Proceedings, 5th International Conference on Water Repellent Treatment of Building Materials”, Brussels, Belgium, 2008, Aedificatio Publishers, pp. 3-16.

34. Selander A, Davant N \& Malaga K: "Hydrophobic Shotcrete - a Method to Waterproof Tunnels," Proceedings, Hydrophobe VII - 7th International Conference on Water Repellent Treatment and Protective Surface Technology for Building Materials, Lisbon, Portugal, 2014, pp. 67-75.

35. Spaeth V, Delplancke-Ogletree M P \& Lecomte J P: "Hydration Process and Microstructure Development of Integral Water Repellent Cement Based Materials,” Proceedings, 5th International Conference on Water Repellent Treatment of Building Materials”, Brussels, Belgium, 2008, Aedificatio Publishers, pp. 245-254.

36. Chauhan R P \& Kumar A: "Study of Radon Transport Modified with Silica Fume," Radiation Measurements, Vol. 59, 2013, pp. 59-65.

37. ICRP. "Lung Cancer Risk from Radon and Progeny and Statement on Radon,” ICRP Publication 115, Ann. ICRP 40 (1), 2010.

38. CEN/TR 17113. "Construction Products - Assessment of Release of Dangerous Substances - Radiation From Construction Products - Dose Assessment of Emitted Gamma Radiation,” European committee for standardization, CEN, 2017, pp. 47. 